\title{
The Research of China's Bicycle Tourism Development under Low-Carbon Economy
}

\author{
Du Li-Juan', Xiao Cong1, Dong Kai-Ling ${ }^{2}$ Zhang Xue-Mei ${ }^{{ }^{*}}$ \\ ${ }^{1}$ Chengdu University, Chengdu, Sichuan, China \\ ${ }^{2}$ Department of Transportation, Chengdu Vocational \& Technical College of Industry Career Technical \\ College, Chengdu, Sichuan, China
}

\begin{abstract}
With the birth of low-carbon economy, low-carbon tourism has been widely concerned by all of the community, the development of low-carbon tourism has become a hot topic of tourists to the government, industries. This paper analyzes the present situation and the trend of the development of bicycle tourism in our country, and discusses the problems existing in the development.
\end{abstract}

Keywords: Low carbon economy; Bicycle tourism; Development

\section{INTRODUCTION}

Sharply with the global climate changing, environmental awareness rising from all life. Bicycle tourism, as one of the healthy, green tourism is highly concerned. People choose to burn fat instead of using gasoline to travel, and it is bound to one of the main form of tourism development in the future. Especially with highly developing under the background of China's economy, the national is improving personal material life at the same time, constant pursuit of personal psychological demand, tourism-as relieve the strain on people, rich personal view of life, to appreciate the natural scenery as the premise, is by the world bicycle travel mode choice, and this tourism will gradually favored by more and more travelers.

\section{LiterATURE REVIEW}

Brent and Hall (1990) studied the bicycle tourism and regional development, Lamont (2009) put forward to the independent bicycle tourism system of the overall point of view. Wan Ya-jun (2008) made a preliminary study on the concept, the type and the significance of development of bicycle tourism in our country. Li Dan (2010) discussed the basic countermeasures of developing low carbon tourism in China.

\section{METHOD}

This paper is on the basis of collecting large number of data, using a quantitative methods. Data were collected, analyzed and discussed in the next part.

\section{ReSUlts AND Discussions}

\subsection{The Current Situation of the Development of Bicycle Tourism}

\subsubsection{The Present Situation of Bicycle Tourism Organization}

Bicycle tourism is still at the stage of spontaneous activities, there are still many deficiencies before riding, most of the bicycle club or bicycle tourism organization use internet, such as the web, forum, blog, QQ, We chat to build communication platform, they make like-minded bicycle travel enthusiasts. Few of the bicycle travel enthusiasts use the way of self-help, and this kind of travel mode greatly 
increased the difficulty of the bicycle tourism. Noticing that, at this stage there are few travel agencies make bicycle tourism into their business cycle. Only a small part of the overall strength of a strong, wide range of business travel agencies began to make bicycle tourism.

\subsubsection{Current Situation of Bicycle Tourism Traffic}

In China, bicycle tourism traffic situation is complicated. Sichuan, Guangdong, as lead of the provinces, which have built a large-scale construction of the bike lanes and green road to meet the needs of bicycle travel enthusiasts. The highway network construction of China developing very fast, which will greatly reduce the traffic flow in different provinces of the original mountain road, the beautiful scenery, the twists and turns of the edge of the countryside road, which is likely to become more clean, more like riding tour of the special highway for bicycle tourism.

\subsubsection{The Current Situation of the Development of Bicycle Tourism Market}

As a big bicycle country, China will undoubtedly occupying the forefront of the world in the bicycle ownership and the using numbers, but the development of bicycle tourism is fall behind to the western countries. According to the survey, college students, white-collar workers and retired workers are the main populations to participate in the tourism activities of the bicycle market. Former two are the elite of the society, but also the main productive forces of the society in the future. With the recent promotion of bicycle green traveling way and its ability to enhance the family affinity, the tourism market is gradually expanding.

\subsubsection{The Current Situation of Bicycle Tourism Resources}

\subsubsection{A Vast and Diverse Topography and Climate}

In Asia, China's geographic and climatic conditions are suitable for the development of bicycle tourism. Beautiful mountains and rivers, hills, plains, lakes and other different landforms, rich and varied, which provide ample room for the riders. North and South cold, warm, tropical temperature difference between the climates is also allowing the riders choose to travel by bike at the whole year.

\subsubsection{A Long History, Rich Cultural Heritage}

China has ancient human civilization in the world, and the urban and rural cultural relics around, in the arrangement of lines it can easily be incorporated into all kinds of historical and cultural attractions ride schedule, which are combined with natural scenery can fully meet the needs of self-driving tourists about the cultural quality tourism ways.

\subsubsection{The Development of Different Forms of Life}

As one of the primary stage of social and economic development of the multi-ethnic country, China is the most abundant social life in the world, the unbalanced economic development in different ways, it makes the life, and all of these create colorful differentiated tourism products, and provide an ideal destination for tourists.

\subsubsection{People is Friendly, Honest and Hospitable}

There is a long traditional warm hospitality of different regions in China, there's no doubt that preparing for the love, love deeply in remote areas and different people riding bicycles contact to the friendliest and warm humanistic environment.

\subsection{Problems Existing in the Development of Bicycle Tourism}

Bicycle tourism is one of the lowest carbon ways for traveling. Compared with other mechanical travel mode, bicycle tourism has its advantages such as the inability to consume low emissions, economical, no pollution, easy for parking and others. But there are some disadvantages, bicycle tourism relative to the train, plane, and car have more advantages, in the process of tourism, it also greatly increases the total travel time of tourists. And bicycle tourism is also affected by the geographical environment, road conditions, climates and the tourists' own physical conditions. 


\subsubsection{Affected by External Conditions}

External conditions refer to the weather and road conditions. The bicycle has the advantages of simple structure, and lack of strict protection, such as inclement weather, which will increase the difficulty of riding, and the rider's body may cause discomfort, which will even affect the ride, the strong sunlight make harm to the rider. The road condition also brings great impact to the ride, such as undulating slopes, will greatly increase the physical strength of the rider's consumption, increase the risk of riding. Bumpy or muddy road, which will not only affect the comfort, but also effect the vehicle and riding equipment damage.

\subsubsection{Requirements for Physical Quality}

Bicycle tourism needs the physical strength of the riders, bicycle tourists need to have good physical quality. First, there must have be plenty of physical strength to finish the long distance riding. Second, a healthy body can adapt to the strong movement of large intensity and the external environment (the weather) strongly change. Third, a quick response in the rapid cycling process, will encounter different road conditions and various emergency situations, requiring riders can timely notice, and quickly make the correct judgment and response.

\subsubsection{Riding Requires more Equipment}

The most important equipment of bicycle tourism is the bicycle, which can be used to the harsh natural conditions and riding for long, the quality and performance of the bicycle (e.g., transmission and suspension) can also put forward to higher requirements. At the same time, the necessary safety equipment, such as helmets, gloves, glasses, etc., is very important to protect the rider's safety, but it cannot be ignored. In addition, long-distance riding, tourists need to prepare all kinds of auxiliary equipment, such as pack, lamps, table, maps, compass, which can also be equipped with maintenance tools and master the basic skills of maintenance, it also needs a collective travel such as walker talking communication equipment.

\subsubsection{Poor Road Safety and Health Condition}

Bicycle tourism inevitably takes a long time to ride on the road, smooth, clean, green good roads can make tourists enjoy riding. However, in many cases the road situation are not satisfied. First, the poor road conditions impact of riding comfort. Second the heavy air pollution which in this environment is difficult to ride for long, and it advises to the health of the body. Third the security problem, many road vehicles in our country are mixed, the complexity of the road on the road cyclists belonging to vulnerable groups, especially riders need to obey the traffic rules and caution problems.

\subsubsection{National Attention is Not in Place for the Promotion of Bicycle Tourism}

In Germany, Holland, France, Finland and other countries, bicycle tourism is being very popular. These countries not only have a dedicated bicycle path, but also provide many bicycle rental stations. For example, Finland also produced a special "guide to the bicycle travel", recommended a variety of entry level tourist bicycle routes. But at present in China, only few areas have built for bicycle path.

\subsubsection{Lack of Protection for Bicycle Tourism}

Bicycle tourism cannot get the maximum protection is still one of the important threats, when facing the ongoing bicycle tourism activities, especially the number of the team increased, the security problem increased. Running alongside other vehicles, riding helmet and gloves are expensive, the lack of uniform ride safety mark or sign, no special planning of bicycle lanes are riding insurance, does not have a security risk issues.

\subsection{Suggestions on the Development of Bicycle Tourism in China}

\subsubsection{Professional Organizations to Provide Related Services}

In view of the rapid development of bicycle tourism trends and future potential development space and lack of surrounding bicycle tourism services, tourism services related to pay enough attention, the 
bicycle tourism into the scope of business, provide professional service. As the bicycle is still in a spontaneous state, there are still many problems in the organizational activities, tourism service agencies which can rely on its rich resources to provide quality services for bicycle tourism. Such as the development of bicycle tourism products: design travel routes, travel services (such as rental bicycles, equipment maintenance, medical aid, food and beverage accommodation, attractions tickets, etc.) can provide to the organization of tourism activities. Some enthusiasts to riding is in afraid, because there is no sure that the road is guaranteed, if we can solve the problem, there will be a great development of bicycle tourism. The travel agency launched around Qinghai Lake in the lake race during cycling tours, but this kind of activity is not enough, which can make the service extended to a large range of time and space.

\subsubsection{Research on the Practical Application of the Bicycle}

Encourage the community to participate in bicycle sports and tourism, promote the healthy and green fashion tourism. Study on the development mode of bicycle tourism, increase the participation of travel agencies, train high-quality tour guides, and standardized management of bicycle related organizations and clubs.

\subsubsection{Planning of Urban Bicycle Traffic System and Bicycle Travel Line}

In our country, there are a large number of people living in the city with a high density, building a bicycle road and encouraging people to ride, it can effectively alleviate the traffic congestion and environmental pollution caused by cars. Open up for the bicycle tour around the island, enjoy the natural scenery, tourist routes, pastoral scenery and accumulate the riding experience, tourism planning, construction along the line of bicycle rental repair and storage facilities, provide guidance and convenient for people to ride.

\subsubsection{The Introduction of Foreign Advanced Concepts of Bicycle Tourism Development}

To strengthen cooperation with foreign bicycle tourism organizations, we provide the latest information and communication platform for domestic bicycle enthusiasts, people can draw lessons from foreign successful experiences of the special planning of bicycle tourism, open up new experiences for domestic tourism activities. The introduction of foreign advanced concepts, is to enhance the domestic people's awareness of bicycle tourism.

\section{Conclusion}

This paper analyzes the current situation, trend and problems in the development of bicycle tourism in China. We get two conclusions:

The rise and development of bicycle tourism are the inevitable trend of the development of the tourism markets. Because of the nature of human beings, we search for the freedom, the tourists are bound to give up the traditional ways in the process of tourism, so people choose a more environmental friendly tourism.

We have good prospects for China bicycle tourism development and great potential, we firmly believe that through the efforts of bicycle tourism growth in China, it will be strongly, and become a force to be reckoned with in tourism.

\section{Notes:}

Key research base of the humanities and social sciences of Sichuan provincial education department : Sichuan provincial leisure sports industry development research center key projects (Number: XXTYCY2017A02).

Chengdu social science 2017 plan project (Number: 2017Z13)

Sichuan provincial education department tourism economic management and exhibition innovation team (Number: 16TD0037). 


\section{REFERENCES}

[1] Ma Xiao-ming, Zhou Xiao-li.(2009). On the "Lake Race" and its influence on Chinese road cycling. Journal of Qinghai University for Nationalities, 2. 165-167

[2] Zhang Jian, Zhou Hai-yun. (2008). The development status and prospect of foreign bicycle tourism. Modern business, 6. 194-195

[3] Zhang Jian, Zhang Chaohui. (2008). The development of bicycle tourism in China the significance. Modern commercial, 8. 196

[4] Liu Shao-cai. (2008). The rise of German bicycle hot. Road traffic management 5. 54-55

[5] Chi Guo-li.(2008). "Paris-Beijing bicycle 2008 dream trip" at the foot of the Great Wall. Yanzhao Metropolis Daily

[6] Qi Jun. (2008). Sports, nature and culture of the depth of the combination of-2008 China Mount Huangshan international mountain bike Festival. World Expo, 12. 87-88

[7] Wu Hao. (2008). Europe and the United States bicycle tourism for China inbound tourism product segmentation revelation. China Travel News

[8] Wan Ya-jun, Meng Rui. (2008). Research and practice on the application of bicycle tourism in China. China bicycle, 353.42-45

[9] Xu Tao. (2007). The popularity of bicycle and modern Shanghai society. Shi Lin 1. 103-112

[10] Liu Jing. (2007). Cycling in Europe. Observation and thinking, 17, 40-41

\section{AUTHORS' BIOGRAPHY}

Zhang Xue-mei (1965- ), female, doctor, master tutor, Chengdu University Professor, main research direction: Tourist Traffic. Published papers 61, presided over the provincial (Department) level research projects 24 , main research 18 , publication of monographs and teaching materials 8 .

Du Li-juan (1981- ), female, assistant researcher, main research direction: Tourism Management, Published papers 3, main research 4.

Xiao Cong (1985- ), male, master, assistant researcher, main research direction: Tourism Economical Management. Published papers 6, main research projects 15, participate in the preparation of 2 works.

Dong Kai-ling (1989- ), male, master, lecturer, main research direction: Tourism Traffic. Published papers 10, main research projects8, participate in the preparation of 2 works. 